University at Buffalo School of Law

Digital Commons @ University at Buffalo School of Law

\title{
Putting "Human Rights" Back into the U.N. Guiding Principles on Business and Human Rights: Shifting Frames and Embedding Participation Rights
}

Tara J. Melish

University at Buffalo School of Law, tmelish@buffalo.edu

Follow this and additional works at: https://digitalcommons.law.buffalo.edu/book_sections

Part of the Human Rights Law Commons, and the International Trade Law Commons

\section{Recommended Citation}

Tara J. Melish, Putting "Human Rights" Back into the U.N. Guiding Principles on Business and Human Rights: Shifting Frames and Embedding Participation Rights in Business and Human Rights: Beyond the End of the Beginning 76 (César Rodríguez-Garavito, ed., Cambridge University Press 2017)

This material has been published in Business and Human Rights: Beyond the End of the Beginning edited by César Rodríguez-Garavito. This version is free to view and download for personal use only. Not for re-distribution, re-sale or use in derivative works. (c) Cambridge University Press 2017.

\section{IN COPYRIGHT}

This Book is brought to you for free and open access by the Faculty Scholarship at Digital Commons @ University at Buffalo School of Law. It has been accepted for inclusion in Contributions to Books by an authorized administrator of Digital Commons @ University at Buffalo School of Law. For more information, please contact lawscholar@buffalo.edu. 


\title{
Putting "Human Rights" Back into the UN Guiding Principles on Business and Human Rights: Shifting Frames and Embedding Participation Rights
}

\author{
Tara J. Melish
}

Framing is critical [to winning a public debate] because a frame, once established in the mind of the reader (or listener, viewer, etc.) leads that person almost inevitably to the conclusion desired by the framer, and it blocks consideration of other possible facts and interpretations. ${ }^{1}$ - Framing expert, George Lakoff

There is a critical question that is too frequently obscured in discussions of the UN Guiding Principles on Business and Human Rights (GPs): Why precisely is it that the most vocal and consistent critics of the GPs are human rights organizations, precisely the groups that have been pushing the longest and hardest for a more effective, non-business-as-usual approach to corporate human rights abuse? Indeed, whether big or small, North- or South-based, international or local in orientation, or highly or loosely networked, human rights NGOs have consistently taken a critical posture toward the GPs. Although their openness to GP engagement has varied, " each has tended to see the GP framework as "regressive," a "step backward" in the protection of human rights, ${ }^{3}$ one based on a corporate good will model that not only has proven itself ineffective over decades of trial and creative experimentation, 4 but that - most revealingly and consequentially - ignores the critical elements of a human rights approach to social change. Indeed, in order to render the GPs

1 George Lakoff, George Lakoff Manifesto 2, www.infoamerica.org/teoria_textos/manifiesto_lakoff.pdf; see also: George Lakoff, The All New Don't Think of an Elephantl Know Your Values and Frame the Debate (2014).

2 Groups that do not take a human rights approach to community-based problem-solving as the primary emphasis of their work have been more open to engaging the GPs. In this respect, I am highly sympathetic to the framing used in Chris Jochnick's contribution to this volume, while believing that it may oversuggest differences in the substance of the critical postures taken by human rights NGOs (as a category) toward the GPs. See infra, note 5 .

3 See, e.g., FIDH et al., "Joint Civil Society Statement on the Draft Guiding Principles on Business and Human Rights" (3 March 2011); Christopher Albin-Lackey, Human Rights Watch, "Without Rules: A Failed Approach to Corporate Accountability," in Human Rights Watch: 2013 World Report (2013) (recognizing GPs as "woefully inadequate" by "setting a lower bar than international human rights standards").

4 Indeed, international efforts at corporate voluntarism in the human rights field have been vigorously pursued at the highest levels since the 1960s. 
acceptable to business, and thereby promote high-level corporate and state buy-in, the very essence of a "human rights approach" to community problem-solving - the core empowerment, participation, and accountability features that make the human rights idiom effective and useful to vulnerable communities and their advocates was systematically removed from the framework and its regulatory logic. The central challenge for human rights groups looking forward, then, is how to put the "human rights" back into the "business and human rights" (BHR) framework, either within the GPs themselves or in some other associated source of "law."

If one listens to John Ruggie - former Special Representative to the Secretary General on Business and Human Rights (SRSG), intellectual author of the GPs, and principal promoter, defender, and publicist of those principles - one will nonetheless come away with a very different answer: Human rights groups, he repeatedly suggests, resist the GPs because they are stubbornly wed to a top-down, old-school model of global governance that has little place in today's highly complex and polycentric world. Indeed, in his campaign-like global efforts to defend the GPs from challenge, and forestall increasingly coordinated efforts to supplement them with more binding and participatory mechanisms (particularly through a new human rights treaty instrument), the former SRSG has adopted a highly powerful and politically resonant frame for understanding international debate on the GPs. ${ }^{6}$

Aiming to move beyond the all-or-nothing "voluntary versus mandatory" frame long dominant in the field, that new frame seeks to resituate international debate along a spectrum of ideal global regulatory response types. That typological spectrum runs from "experimentalist" or "polycentric" governance regimes or regime complexes at one end (often gathered under a "new governance" heading) to rigid "command-and-control" treaty regulation on the other. Through this frame, the former SRSG is able to shift the axis of debate in a new direction while continuing to draw sharp and categorical distinctions between the GPs and the model they replaced, the UN Norms on Business and Human Rights (Norms). ${ }^{7}$ Though

5 Human rights NGOs have tended to respond to the GPs in one of two primary ways: by rejecting their utility outright for influencing human rights conditions on the ground or by recognizing their utility in limited respects while insisting on their direct supplementation with additional human rights tools, instruments, and procedures to bring them, at a minimum, back into line with the hard-fought international standards already recognized in the human rights field. This is particularly true regarding the framework human rights principles of participation, accountability, nondiscrimination/equality, empowerment, and legality of rights, known as the "PANEL" principles.

6 John Ruggie's recent book, Just Business: Multinational Corporations and Human Rights (Norton 2013), is a revealing firsthand account of the campaign-like strategies of "meaning management" and staged endorsement the former SRSG has undertaken at the highest levels to promote the GPs, distance himself and his framework from human rights NGOs, and gain the backing of the business community and powerful states.

7 As Professor Ruggie openly acknowledges, his "first official act [as SRSG] was to commit "Normicide"" - designed to establish a "clean break" from the Norms and, consequently, open the door to constructive engagement with the business community. It was achieved by concluding in his first official report - in "deliberately undiplomatic language" - that the Norms suffered from "exaggerated legal claims" and were "engulfed by [their] own doctrinal excesses." See Just Business, supra, 
strongly supported by human rights groups, those Norms were of course rejected by the business community and failed to win approval within the UN Human Rights Commission in 2005, giving direct rise to the SRSG's mandate and process of drafting the GPs.

The new frame operates by jointly locating the Norms and civil society calls for a comprehensive human rights treaty at one extreme end of the regulatory spectrum. They are based, the former SRSG insists, on an antiquated treaty-based regulatory model that has proven itself ineffective and ill-suited to modern global challenges. That traditional model - top-down, rigid, and highly prescriptive - presumes there is a singular "one-siże-fits-all" approach to global problem-solving that every actor, everywhere, must uniformly adopt. ${ }^{8}$ The human rights paradigm, says the former SRSG, is based on this rigid model, with advocates continually insisting there "ought to be a law, one single international law, which binds all business enterprises everywhere under a common set of standards protecting human rights." Although human rights NGOs cling religiously to this model, the former SRSG asserts driving him "batty," as he likes to say, with their insistence that it is the only way forward - the model represents a nonstarter approach that, in contrast to the GPs, will offer no practical relief or recourse to real people in real situations on the ground. $^{10}$

The GPs, by contrast, are located at the opposite, happier end of the global regulatory typology. They are presented as a fresh and innovative example of a new global legal pluralism that takes a "polycentric" or "new governance" approach to global problem-solving." This "new" approach appreciates and values the diversity of stakeholders that need to be constructively engaged in twenty-firstcentury problem-solving (including particularly businesses themselves), the plural

pp. 54, 158. Ruggie regularly attributes the same "excess" to human rights groups calling for more - mandatory supplementation to the GPs.

8 See, c.g., John J. Ruggie, "A UN Business and Human Rights Treaty? An Issues Brief," (28 Jan. 2014), 3-4; John Ruggie, "International Legalization in Business and Human Rights," Remarks delivered at presentation of the Harry LeRoy Jones Award of the Washington Foreign Law Society, Washington DC (11 June 2014), P. 4 ("One would think that this [top-down approach to international lawmaking, which seeks to squeeze the entire bundle of $B \& H R$ challenges into a single, all-encompassing treaty] would have lost its appeal by now, given its repeated failure to produce meaningful results").

9 Just Business, p. 55. See also John Ruggie's contribution's in this volume. The charge in fact turns the "human rights paradigm" on its head.

10 See, e.g., Ruggie Remarks, ibid., note 8, p. 6 ("From the vantage of victims, an all-encompassing [B\&HR] treaty negotiation is not only a bad idea; it is a profound deception."); John G. Ruggie, Letter to Editor, "Bizarre Response by Human Rights Groups to UN Framework Plan," Financial Times (19 January 2011) ("Do Amnesty and the [other human rights NGOs] really urge [the GP framework's] defeat - delivering 'nothing' to victims yet again? How much longer will they ask victims to wait in the name of some abstract and elusive global regulatory regime when practical results are achievable now?").

11 ·John Gerard Ruggie, "Global Governance and 'New Governance Theory': Lessons from Business and Human Rights," Global Govemance 20 (2014), 5-17 (describing GPs as "an exercise in polycentric governance"). 
governance regimes they in fact respond to in their day-to-day operations (corporate, public, and civic), and creative ways for aligning interests across these distinct and insufficiently intersecting regimes. The GPs are conceived to do precisely that, Ruggie asserts, and it is for this reason they have received such widespread support and institutional uptake across stakeholder groups.

Deftly and repeatedly promoted by the former SRSG in his regular GP talking points and frequent public lectures, the frame is a highly effective strategy for promoting the GP project as the only real game in town. It creates a cognitive frame that, by placing the GPs at one ideal-type extreme and a comprehensive human rights treaty on the other, leads the listener almost inevitably to the framer's desired conclusion: the GPs are good - their supporters are reasonable, flexible, and responsive to real world outcomes; comprehensive human rights treaties are bad their supporters are rigid, doctrinaire, divisive and shortsighted in their singular quest for a treaty-based "silver bullet" that is hopelessly outdated and nonresponsive to the complexity and polycentricity of real-world problems. ${ }^{\text {.2 }}$

Though grossly misrepresentative of the actual "positions of the parties, ${ }^{13}$ the heuristic serves the GP project well. ${ }^{24}$ It guarantees steady business and Global North support of the GPs and GP implementation process (by framing their alternative as direct international legal regulation). It sidelines good faith calls for new treaty-based tools of accountability and participatory empowerment as extremist and regressive, blind and indifferent to the actual day-to-day needs of real people on the ground. It casts defenders of the GPs, including powerful businesses and Global North states, as the "true" defenders of human rights progress in the B\&HR field. It also casts human rights NGOs (the GPs strongest and most effective critics) and the growing number of Global South states supportive of a new treaty instrument in the field as obstacles to real progress, stubborn, and myopic in their ideological

12 See, e.g., John Ruggie, "Progress in Corporate Accountability" (4 February 2013) (deriding human rights calls for more mandatory supplementation of the GPs as hopelessly based on "some idealized global command-and-control regulatory regime" that "risks turning the clock back rather than moving us forward").

13 Indeed, human rights groups are not now, nor ever have been, advocates of rigid command-andcontrol regulation - and no human rights treaty has ever even remotely followed this approach. To the contrary, human rights advocates have for decades been at the forefront of global efforts to incorporate greater experimentalist and new governance features into regulatory regimes, particularly around increased stakeholder voice and participation, multiple and intersecting monitoring and accountability arrangements, interpretive flexibility, and responsiveness to local community-based priorities and understandings. This is core to what the "human rights framework" demands. Meanwhile, the GPs have come under heaviest attack for their failure to adopt the central features of "new governance" or experimentalist regime types. See Tara J. Melish and Errol Meidinger, "Respect, Protect, Remedy and Participate: 'New Governance' Lessons for the Ruggie Framework," The UN Guiding Principles on Business and Human Rights: Foundations and Implementation (ed.), R. Mares (Martinus Nijhoff Publishers 2012).

14 See Rodríguez-Garavito contribution in this volume (defending use of typology as merely a "heuristic"). As framing theory teaches, heuristics can misdirect thinking and action as much as they can direct it. 
extremism and "doctrinal excess," " and hence justifiably sidelined in the process of implementing the GPs and their "new regulatory dynamic." The frame thus leads, by design, not only to the general conclusion that human rights groups and other civil society NGOs can, even should, legitimately be bypassed in the GP implementation process (including in the work of the new UN Working Group tasked with its promotion), but also - most relevantly for this volume - toward proposals for moving the GPs "beyond the end of the beginning" that maintain intact the framework's elite-centred, internationalist, and voluntarist logic, while merely tinkering with details at their outer margins. Indeed, by seeking "intermediate pathways" between the two ideal regime types, such proposals lose the core of what is at stake and actually in contention.

It is here that my central critique of the original background contribution to this volume by César Rodríguez-Garavito rests. Although the author correctly identifies the principal deficiency of the GPs from a human rights (and new governance/ experimentalist) perspective ${ }^{16}$ - that is, the framework's failure to take systematic and explicit account of the critical role played by "empowered civil society participation" in closing the massive governance gaps that pervade the field - the author's uncritical embrace of the former SRSG's frame ${ }^{17}$ leads him to a bewilderingly impoverished set of proposals for addressing that deficiency. The chapter is thus a powerful testament to the effectiveness of the former SRSG's chosen frame. It demonstrates how that frame not only leads large numbers of listeners to the "conclusion desired by the framer" (that the GPs are the only real game in town, and hence efforts to expand their content in the form of a treaty or other regulatory instrument are either fundamentally misguided or simply impractical), but also "blocks consideration of other possible facts and interpretations, ${ }^{\prime 8}$ including, most critically, the actual reasons human rights NGOs insist that the GPs require more mandatory and expressive supplementation.

A new frame for situating international debate on the GPs is critically needed. Part I below offers what I see as a far more accurate frame. Parts II and III then use this frame to rethink answers to the two key questions identified by RodríguezGaravito for constructively taking the GPs "beyond the end of the beginning": How can "empowered civil society participation" effectively be incorporated into the

15 See note 7 above.

16 For an analysis of the overlap between "new governance" and "human rights" approaches to regulatory problem-solving, see Tara J. Melish, "Maximum Feasible Participation of the Poor: New Governance, New Accountability, and a 21st Century War on the Sources of Poverty," Yale Human Rights and Development Law Journal 13: 1 (2010).

${ }^{17}$ See Rodriguez-Garavito in this volume. In the original background version of his chapter, the author locates the GPs within a typology of global regulatory responses that, he asserts, runs from "treatybased regulation" at one end of the regulatory spectrum to "voluntary standards and polycentric governance" at the other end. He then locates the GPs at the latter end, and incorrectly calls it "new governance."

18 See note 1 above. 
GPs' "dynamic logic"? And what role, if any, does a human rights treaty instrument have to play?

\section{SHIFTING FRAMES: COMPETING THEORIES OF SOCIAL CHANGE}

If the principal competing visions of the GPs do not run along an "experimentalist versus command-and-control" spectrum, along what continuum do they run? As I see it, the core international debate on the GPs is one that straddles not two distinct governance or regulatory regimes, but rather two distinct theories of how social change or system transformation is most.effectively influenced in complex, powered society. It is the fundamental divergence between these two theories of social change and, most importantly, the respective toolsets required to advance them that explains human rights NGOs' skepticism toward the GPs. Let me explain.

Like other UN global design projects.that John Ruggie has played a leading role in developing (e.g., the Global Compact and Millennium Development Goals), the GPs are based on a particular acculturative theory of system transformation, known in international relations theory as social constructivism or sociological institutionalism. Professor Ruggie is an important intellectual progenitor of this theory. ${ }^{19}$ Very simply stated, ${ }^{20}$ the theory posits that individual actors in global society (states, business entities, civil society groups) act in particular ways primarily because they are socialized into certain behavioral patterns, largely by the shared norms and norm-informed practices of their self-identified global reference groups. The most effective way to modify "bad" behavioral patterns within such groups is thus to influence the shared cultural systems through which appropriate conduct is normatively defined in a given community. A particular methodology is identified to affect this normative shift. It has three core components: (1) "authoritative" adoption of a standardized international script for global uptake, (2) structured and framed in a way that will promote voluntary buy-in and formal uptake by the relevant reference groups, and (3) promotion of international processes designed to stimulate elite engagement with script norms and other reference group elites, leading to voluntary uptake, mimicry, and standardization of policy forms across the group.

Through these elite engagement processes, it is theorized, norms come to be seen as part of the reference group's self-identity. When this "tipping point" is reached, individual components of the global script become embedded and internalized as a new set of constitutive rules that define and prestructure the scope of socially

19 See, e.g., J. G. Ruggie, "What Makes the World Hang Together? Neo-utilitarianism and the Social Constructivist Challenge," International Organization 52:4 (1998), 855-885.

2o For a more complete description in the GP context, see Melish \& Meidinger, note 13 above. For Ruggie's own description, see above. 
acceptable conduct in the field. ${ }^{21}$ The resulting taken-for-granted quality of the underlying norms is henceforth able to resolve the misaligned incentive structure and collective action problems that, in the BHR context, the former SRSG attributes to the absence of consensus regarding appropriate policy forms and outcomes. Keeping businesses and states engaged in the GP "implementation process" understood as formal uptake practices across a widening group of actors - is thus fundamental to the project's "success." It explains the former SRSG's confident pointing to elite international (OECD, IFC, EU, AU, ASEAN, ISO) formal uptake practices as "evidence" of successful GP implementation (wholly independent of any translation into policy change on the ground). ${ }^{22}$ It also accounts for his resistance to, even antagonism toward, civil society's insistence on more mandatory norms and other participatory levers for engaging in "accountability politics" from below, as well as the UN Working Group on BHR's steely focus on script dissemination and high-level corporate actor engagement in its international meeting spaces (rather than serving a role more akin to other Human Rights Council Special Procedures, which tend to prioritize spaces for civil society engagement).

Human rights groups; by contrast, tend to view this account of social change as simplistic, naïve, and incomplete. They insist that genuine social transformation occurs only when affected communities themselves have the power and voice to engage decision-making processes that affect their lives, as active subjects of law, not mere objects. From their perspective, human rights abuse occurs for one primary reason: powerlessness. People will continue to be abused while they lack power power to understand, to challenge, to confront, and to engage the causes and conditions of their abuse. Critically, they must do this themselves, as active subjects of the law, not passive objects thereof. Indeed, any model of change based on other people - especially the very ones responsible for misconduct - doing this for them (whether out of humanitarianism or direct self-interest) is misguided at best, a status quo power play at worst. Interests are too strong, and the power of dominant groups to whitewash, elide, ignore, agenda-set, influence-peddle, and misrepresent too great. $^{23}$

The GPs are a "step-backward" for human rights groups, then, for two related reasons. First, they fail to recognize the essential role that rights-holders themselves

${ }^{21}$ See, e.g., Just Business, pp. 166-169 (describing GPs implementation logic in terms of three phases of the "life cycle of norms" - norm emergence, norm cascade, and norm internalization - and concluding that "[a]mong the main international standard-setting bodies" and "leading multinational corporations" the first two phases are effectively complete, while the latter phase has just begun). Iust Business, Pp. 121-123 (triumphantly describing "swift uptake" of GPs by international standard-setting bodies); John J. Ruggie, "A UN Business and Human Rights Treaty? An Issues Brief," (28 Jan. 2014), p. 2 (same, while conceding that "no systematic assessment is available of overall results to date").

23 For a powerful overview of the corporate sector's highly organized public relations strategies aimed at reframing the UN agenda on B\&HR, see Jens Martens, "Corporate Influence on the Business and Human Rights Agenda of the United Nations" (Working Paper, Brot für die Welt/Global Policy Forum/MISEREOR, June 2014). 
play in identifying (indeed defining what constitutes) abuse, its causes, and contextually appropriate mechanisms, arrangements, and procedures for preventing it in the first place. Instead, the GPs envision processes of human rights policy development and decision-making as unfolding in a primarily top-down unidirectional fashion, with corporate actors determining what is required consistent with corporate self-interest and self-identity (and isomorphic mimicry of forms). That is, driven by elite-centered ideational incentives and the idea that corporations are or should be human rights leaders as a matter of constructed self-identity, the GPs contemplate no power shift between stakeholders whatsoever. Corporations and powerful states are the active agents and norm entrepreneurs at their "dynamic" center, while rightsholders and their civil society advocates remain bystanders and onlookers, passive "beneficiaries" of outsider good will. Indeed, while corporations "should" consult with such communities, they have no obligation to nor consequence for not so doing.

It is this disregard for direct rights-holder engagement and participatory access to agenda-setting processes that leads to the second core human rights critique of the GPs: The framework's failure to offer.any express tools or legal resources to affected communities such that rights-holders themselves have the power and capacity to engage the causes of their own abuse. ${ }^{24}$ Such rights-building tools would enable communities to better understand the field-specific scope of their rights, the necessity of community-based mobilization around them, the correlate duties held by other social actors (both substantive and procedural), and how such duties may effectively be leveraged to shift the dynamics of decision-making toward the protection of human rights, in locally responsive ways. This deficiency is true both in the inexpressiveness of the GPs' terms (in relation to both rights and duties) ${ }^{25}$ and in their lack of reference to any rights of participation or institutional pathways for the realworld exercise thereof. Given the massive power and information disparities that prevail in the corporate domain, such legal resources are vital for the exercise of bottom-up accountability politics by vulnerable communities. ${ }^{26}$ It is little wonder,

24 As used here, "legal resources" refer to those normative tools and institutional pathways through which affected persons and communities can know their rights, stand up to defend them when aggrieved, and actively engage in the day-to-day praxis of empowered participatory governance in matters that affect their lives. See generally Clarence J. Dias and James C.N. Paul (1985), "Developing Legal Resources for Participatory Organizations of the Rural Poor," Third World Legal Studies Vol. 4 , Article 2.

25 The GPs have been recognized as a primary exemplar of an "inexpressive international instrument" given their failure to articulate clear commitments on the part of social actors, to which other social actors can hold them to account. See Andrew K. Woods, "Inexpressive International Agreements" (unpublished manuscript on file with author).

26 Accountability, in this regard, means that "some actors have the right to hold other actors to a set of standards, to judge whether they have fulfilled their responsibilities in light of these standards, and to impose sanctions if they determine that these responsibilities have not been met." R. W. Grant and R.O. Keohane, "Accountability and Abuses of Power in World Politics, American Political Science Review 99 (2005), 29. 
then, that the GPs have attracted so little knowledge or buy-in by affected communities anywhere in the world. They simply lack the tools to be meaningful or relevant to local level struggles against corporate abuse.

The result is a BHR governance regime fertile with opportunities for "creative compliance" and other forms of "greenwashing" or "decoupling." That is, companies predictably take the cue to engage in highly formalistic uptake practices designed to legitimize brands and avoid exposure by activists, while failing to engage in any genuine ground-level operational change. ${ }^{27}$ Examples abound. Such examples give direct voice to the human rights concern that ideational incentives and voluntary efforts to "know and show" will not, by themselves, meaningfully change conduct on the ground. Localized, independent, and regular checks on power and interests, backed by the credible threat of material consequences and penalty defaults (whether social, economic or legal) by those stakeholder groups most affected by corporate misconduct, are indispensable to "success." ${ }^{88}$ To do this, however, rights-holders need to be recognized as central to the process of defining problems, envisioning solutions, setting agendas, destabilizing expectations, monitoring compliance, and incentivizing behavior. Equally critically, to ensure rightsholders can exercise those roles in fact, they need to be provided an expressive set of rights-based leverage tools for asserting their voice and socially amplifying their power. $^{29}$

It is toward remedying these two deficiencies that NGO calls for more mandatory and expressive GP supplementation - particularly through a human rights treaty are directed. As I read them, such calls seek three primary things: (1) more expressive commitments on the part of global actors that set clear principles and broad standards and goals for achievement (not rigid, one-size-fits-all rules, which, by definition, are not responsive to local needs and experiences); (2) a framework and instituted processes through which those goals can be pursued by the full range of stakeholders, including particularly those most affected by corporate misconduct; and (3) express rights of participatory engagement to enable rights-holders themselves to

27 The GPs' limited “remedy" prong provides little meaningful relief in this context. It does not entitle affected communities to engage in problem-solving, agenda-setting, and regular monitoring of business-related human rights harms, but rather only to seek (allowable) redress once discretionary abuse has already occurred.

28 For an important example, see the Coalition of Immokalee Workers Fair Food Program, described as "one of the great human rights success stories of our day" and "the best workplace monitoring program" in the United States. See http://ciw-online.org/fair-food-program. See also Melish, "Maximum Feasible Participation of the Poor," note 16 above (describing strategies of "new accountability" movements across Global South and North).

29. See generally Gráinne de Búrca, Robert O. Keohane, and Charles Sabel, "New Modes of Pluralist Global Governance," NYU Joumal of International Law o Politics 45 (2013) (concluding that "successful" experimentalist governance regimes and practices "depend on extensive and open participation of civil society actors in agenda setting, revision, and ongoing problem solving... Enlarging the circle of decision-making, and keeping it accessible to new participants is a condition of success) (emphasis added). For an application of this argument in the human rights arena, see Melish \& Meidinger, note 13 above. 
engage the framework on an equal basis alongside other stakeholders, including accounting for failures.

Such calls, it demands emphasis, are consistent not only with a human rights approach to social change (with its focus on promoting the agency, power and dignity of the socially situated rights-holder), but also with the very logic of experimentalist governance. Indeed, genuine experimentalist systems are recognized to be constituted by four core elements: 1 ) the articulation of a broad framework for setting general goals or standards in a participatory manner; (2) local units (public and private) pursuing the goals in locally appropriate ways; (3) regular reporting and peer review by a variety of stakeholders; and (4) a system for revising goals, metrics and decision-making procedures "by a widening circle of actors in response to the problems and possibilities revealed by the review process." $3^{\circ}$ The GPs and their UN follow-on activities are neither structured nor envisioned to do any of this. Rather, they merely assume that it will be done by others - somewhere, somehow ignoring entirely the power differentials and structural barriers that prevent it from happening in fact. To frame them as "experimentalist" and "polycentric" thus not only misapprehends what is required of such governance regimes - namely, open stakeholder access and exercisable rights of participation at all stages of design, monitoring, accountability, and review - but dramatically distorts the lines of debate about what critics find wanting in the GPs and how they wish to update them.

Reframing the debate is critical. By more accurately understanding international debate on the GPs as a contest between those who advocate elite-driven acculturation-based models of social influence (the former SRSG, the WG, corporate interests, many Global North states) versus those who insist on bottom-up accountability politics (affected communities, human rights NGOs), ${ }^{31}$ the contours of where "intermediate pathways" lie becomes much clearer. Indeed, assertions to the contrary notwithstanding, human rights advocates do not reject acculturationbased strategies (like the GPs) when promoted as, one of multiple relevant and important strategies of social influence. ${ }^{32}$ What they "reject" in the GP framework

Sabel and Zeitlin, "Experimentalist Governance," in D. Levi-Faur (ed.), The Oxford Handbook of Governance (Oxford Univ. Press 2012), 169-183; see also "New Modes of Pluralist Global Governance," note 30 above (identifying five similar components).

32. While human rights NGOs uniformly insist on more mandatory or expressive rights of civil society participation, independent oversight, and accountability, they do differ in their willingness to speak "for" affected communities in exercising those rights. On a typological spectrum running from pure acculturation-based strategies of social influence to pure power shifting ones, then, some will locate at the extreme latter end, while others will move toward a more centered position, explaining their higher openness to GP engagement. Compare Chris Jochnick, Chapter 7 , in this volume.

By focusing on the operational limits of the Working Group and hence recommending the "replacement" of its current mandate with a different, more rights-holder centered mandate, RodríguiczGaravito nonetheless moves oddly (and seemingly unwittingly) in this direction. The better option would be to envision different orchestrational bodies or sites for engaging these distinct modalities of influence, as other treaty-based human rights regimes do. See, e.g., CRPD and its Optional Protocol (creating an oversight committee with periodic reporting and individual complaints functions and, separately, a Conference of States Parties for peer-to-peer stakeholder learning). The creation of 
is the virtual unitary focus on top-down acculturative dynamics, together with its promoters' dismissiveness, even antagonism, toward more rights-holder-centered and bottom-up accountability strategies. These latter strategies, human rights groups insist, are indispensable not only in themselves, but also for the very viability of norm-based acculturation processes; they serve to ensure that a "logic of consequences" spurs, incentivizes, destabilizes, and disrupts logjams in processes geared toward embedding a "logic of appropriateness." 33

Indeed; as even acculturation-based models' most ardent defenders acknowledge, acculturative forces do not invariably increase respect for human rights; they may in fact lead to worsening and more dangerous human rights conditions on the ground. ${ }^{34}$ Designing a human rights regime exclusively, or even primarily, around such forces is thus shortsighted and counterproductive. Rather, optimal human rights regime design requires that attention be given not only to interest discovery among elite players, but also to interest conflict and how less powerful actors seek to narrow power asymmetries through organized mechanisms of social (legal, economic, political) leverage. A "business and human rights" framework makes little sense without it. Human rights NGOs and affected communities should thus be expected to continue to reject the GP framework as "the authoritative focal.point" in the B\&HR field ${ }^{35}$ - or even "authoritative" at all ${ }^{36}$ - while rights-holder empowerment and participatory engagement are not made a more systematic institutional feature.

\section{'II EMPOWERED CIVIL SOCIETY PARTICIPATION: HOW TO GET THERE?}

Consistent with the above critique, Rodriguez-Garavito rightly focuses on the need for greater attention in the GP framework to "empowered civil society participation" and the availability of institutional pathways for the exercise of countervailing power. Nevertheless, by falling for the framing convention set out by the former SRSG, his reference points become skewed and he ends up advancing proposals that bear little relationship to the actual problem diagnosed. In short, he advances two proposals for moving the GP implementation process forward: (1) pursue a treaty, but one narrowly limited to corporate responsibility for "gross" human rights

a separate UN Special Rapporteur on B\&HR, to complement the work of the current Working Group, would be a first step in this direction.

33 John Ruggie seems to recognize this in his early work as SRSG. See, e.g., J.G. Ruggie, "Business and Human Rights: The Evolving International Agenda," American Joumal of Intemational Law 101 $(2007), 836$. "The Achilles heel of self-regulatory arrangements to date is their undeveloped accountability mechanisms").

34 R. Goodman and D. Jinks, "Incomplete Internalization and Compliance with Human Rights Law:

A Rejoinder to Roda Muchkat," European Joumal of Intemational Law 20 (2009), 443-444.

35 The former SRSG continually presents and promotes the GPs as such.

${ }^{36}$ Accord Bonita Meyersfeld, Chapter 11, in this volume. 
violations (and states' associated extraterritorial obligations); and (2) replace the current mandate of the UN Working Group (WG) tasked with GP orchestration with one more like other UN special procedures in the human rights field. Neither, I contend, will have any appreciable effect on shifting power to vulnerable communities.

Simply stated, the treaty proposal errs by assuming (in line with the SRSG's frame) that the "comprehensive treaty" desired by human rights NGOs is one that would rigidly codify a set of highly prescriptive rules for corporations that every business entity, everywhere, must uniformly adopt. Understood as such, the logical "intermediate pathway" between' the GPs' current "dynamic logic" and civil society's preferred "treaty route" lies precisely where Ruggie and the author jointly locate it: (1) reducing the subject-matter scope of the desired command-andcontrol treaty (hence the former SRSG's insistence on a "precision tool"); and (2) limiting its jurisdictional application to those few "bad apples" who are uninfluenceable by the elite-driven social constructivist logic of the GPs - that is, those engaged in the "worst of the worst" violations rising to the level of international crimes (genocide, war crimes, crimes against humanity, etc.). ${ }^{37}$ The proposal, concededly, makes perfect logical sense under one critical condition: you buy into the frame. If you don't, it entirely misses the mark. Indeed, by misidentifying the position of human rights NGOs (who favor a very different kind of "comprehénsive treaty," I believe), ${ }^{38}$ the proposal is entirely nonresponsive to the "countervailing power" critique. It fails to create any new tools of participatory empowerment or institutional engagement for the millions upon millions of communities the world over affected by negligent and abusive conduct in the business domain. The proposal instead favors a regime that states have already rejected in the Rome Statute, ${ }^{39}$ and that will be so politicized, distracting, and selectively deployed (given the Global North's power and structural interest in protecting its own) - and so dominated by the usual narrow band of international criminal law suspects - as to be nonrelevant to local struggles and actors on the ground.

The WG proposal is similarly deficient, but for a different reason. By focusing on international "orchestration," it puts the cart before the horse. It fails to address the core reason so few affected communities know or care about the GPs in the first place and hence have reason to substantively engage them at all, at international or local levels. Indeed, if the type of "empowered civil society participation" that the human rights critique envisions is to be incorporated into the GPs' "dynamic" implementation logic, the GPs themselves must acknowledge it and provide some

See, e.g., John Ruggie, Chapter 2, in this volume.

Negotiators of the Rome Statute expressly declined to extend its jurisdiction to "legal persons," like corporations, for participation or complicity in precisely the international crimes identified in the Ruggie proposal. Why states would change their positions on this so quickly is unclear to me, especially as national trends seem to be moving in the opposite direction. And if they did, why create a new instrument rather than simply amend the Rome Statute or create an optional protocol thereto? 
set of locally meaningful tools to promote it and hence enable local buy-in. Without doing this, creating limited new spaces for engagement in international WG activities will serve only to increase the marginal participation of those civil society actors who are already empowered to participate in high-level fora like the $\mathrm{WG}_{\text {, }}$ and, to a large extent, are already participating therein (albeit to a lesser degree than corpotate interests)..$^{\circ}$

A far. more basic update to the GPs and their implementation logic is required. In a 2011 piece, Errol Meidinger and I proposed one way that key participatory empowerment tools could be incorporated directly within the GP framework. We proposed incorporation of a fourth "Participate" pillar into the "Protect, Respect and Remedy" Framework (enlarging it modestly to a PRRP Framework). ${ }^{41}$ By building express recognition of the critical role of civil society actors directly into the GP framework itself, we envisioned three distinct but closely related value-added benefits. First, it would elevate an expressive commitment to the participatory rights of civil society actors to the same normative platform held by state and corporate actors, thereby providing a normative base from which they could demand equal attention and participation in the implementation process. Such a platform would make it difficult for state and corporate actors to simply dismiss or sideline civil society actors, as they so frequently do, in the process of constructing national action plans, new regulations, "human rights due diligence" processes, and community "consultation" designs, consistent with their (inexpressively framed) duties under the current GPs. In so doing, it would likewise serve to complement, contextualize, and dynamize the "Remedy" pillar, making clear that affected communities are not simply post-hoc grievance holders, entitled to speak up and be heard only after harm has occurred. Rather, it would recognize unmistakably that they have critical and indispensable roles to play at all stages of decision and policymaking affecting their lives - including at the design stage, before harm occurs, and in continual monitoring, agenda-setting, awareness-raising, and review processes.

Second, and most instrumentally, incorporation of a fourth "participate" pillar would provide the structural foundation for the concrete elaboration of a series of cross-cutting (and expressively framed) GPs dedicated specifically to operationalizing a participatory role for civil society actors, at each key stage of "implementation." Applicable across public law and corporate governance systems, such operational principles would recognize civil society's right to participate in, for example, the preaward review of concession contracts; the conduct of prior impact studies; the development of National Action Plans; ${ }^{42}$ the independent monitoring and review

See also contribution by Bonita Meyersfeld in this volume (noting that the GPs have been engaged by "empowered actors in empowered places").

See Melish \& Meidinger, note 13 above.

For an important effort in this regard, see Danish Institute for Human Rights \& International Corporate Accountability Roundtable, National Action Plans on Business and Human Rights: A Toolkit for the Development, Implementation, and Review of State Commitments to Business and Human Rights Frameworks (June 2014), PP. 42-44 (calling on all governments to develop NAPs and to 
of corporate grievance procedures, due diligence plans, and complaint mechanisms; as well as other recognized national and international-level monitoring and accountability arrangements. They would also include key safeguards regarding access to information, transparency, and participatory accessibility, as growing numbers of treaties have done in BHR related fields, including corruption, the environment, and the workplace. ${ }^{43}$ By expressly recognizing these cross-cutting participatory governance principles as central to the duties to "protect" and "respect" in the framework, key levverage points would be created through which civil society actors could more meaningfully insert themselves, as a matter of right, into a wide range of on-the-ground implementation processes. ${ }^{44}$ The experimentalist character of the framework as a whole would thereby be strengthened, far more actors would be induced to engage it, and hence far larger "cumulative effects" could be generated across governance domains. ${ }^{45}$

Third, and again closely related, an expressive set of rights and participationenabling duties under a fourth pillar would serve to enhance and expand sites of independent implementation oversight, especially those most accessible and normatively open to rights-holder engagement. Indeed; because the GP framework does not contemplate specific institutional mechanisms of independent compliance oversight (such as an individual complaints procedure or periodic reporting regime), a "participate" pillar would provide important normative contact points with the existing human rights architecture, including National Human Rights Institutions, UN special procedures, and human rights tribunals (national, regional, international). For such bodies, rights-holder participation, voice, agency, and access are guiding framework principles. While the former SRSG likes to reference the "implementation" capacities of international investment, banking, financial, and other "economic law" institutions, including OECD National Contact Points, these are not the kinds of procedures to which affected communities have ready access or to which they are likely to turn. Creating more contact points with national and international institutions designed to promote and defend the rights of the least

ensure effective participation by all relevant stakeholders through stakeholder mapping, capacitybuilding, and ensuring participation by disempowered or at-risk stakeholders).

See, e.g., UN Convention Against Corruption, pmbl., arts. 5, 6, 10 and especially i3 ("Participation of Society"); Convention on Access to Information, Public Participation in Decision-Making and Access to Justice in Environmental Matters (Aarhus Convention) (1998); UN Convention on the Rights of Persons with Disabilities, pmbl., arts. 4.3, 33, etc. [hereinafter CRPD].

44 A "participate" pillar would thus function in a parallel manner to the "remedy" pillar. While that pillar may formally be cast as a "duty" or "responsibility" in the framework, it is in practice regularly invoked as a right of civil society actors, including by the former SRSG. See, e.g., "Global Governance," note 11 above, Pp. 5, 9 ("For affected individuals and groups, the GPs stipulate ways for their further empowerment to realize the right to remedy.") (cmphasis added).

45 In this sense, the proposal fit seamlessly into the former SRSG's emphatic articulation of the core aim of the GP framework: to close regulatory gaps by creating more effective and dynamic alignment between state, corporate and civil society governance systems, allowing each, to mobilize more effectively to reinforce each other's strengths, address each other's weaknesses, and act as mutual balance and accountability checks. See, e.g. Just Business, p. 78 . 
powered is thus critical. This is particularly true in light of the increasing "fragmentation" of international law, and hence imperative of finding ways to promote interpretive convergence across governance regimes, ${ }^{46}$ while, at the same time, helping to ensure that the GPs do not continue to fall behind evolving standards in the human rights field.

Other longer-term methods could of course be proposed for achieving similar ends outside the GP architecture. One good example - one I support, as detailed below - is the adoption of an international treaty instrument expressly recognizing the participatory rights and roles of civil society in all stages of the implementation process, as other recent human rights treaties have profitably (and without controversy) done. ${ }^{47}$ Our proposal was simply that the same expressive commitment made to "respect," "protect," and "remedy" should be made with respect to civil society "participation," recognizing it not only as a right under international law but as an indispensable element of polycentric governance regimes. One that both state and corporate actors have a duty/responsibility to ensure, and which, as a cross-cutting and intersectional principle of human rights law, requires its own set of guiding principles to ensure effective operationalization across governance systems. Without this being done, we were confident that the issue of participation would be reduced to a side-note and taken off the table..$^{4}$ Indeed, as the initial volume contribution itself recognizes, the GPs do not incorporate civil society participation as a systematic institutional feature in their current elaboration, stating merely and weakly that corporations should "consult" with potentially affected communities in assessing human rights "risks" (Principle 18). Whether they do so or not, and, most critically, how they do so, is entirely up to their own discretion. Stated another way, within the present GP framework civil society actors are left bereft of any express normative toolset to demand their effective participation in GP implementation processes as a matter of right.

It is useful to recall in this regard, the literature on expressive commitments in international (and national) law. That literature understands expressiveness as one of the key functions of law. It allows states and other actors to clearly and publicly manifest a commitment to some principle above and beyond whatever obligations are imposed. That public manifestation of commitment serves important intrinsic and instrumental ends. Most significantly, it allows a range of social actors to hold those who commit to account for their commitments. ${ }^{49}$ Critically, this is true

46 Ruggie, "Global Governance," note 11 above (noting impacts of fragmentation).

47 CRPD, note 44 above, arts. 43 , etc.

$4^{8}$ In the 2014 conference giving rise to this volume, Professor Ruggie objected that such a "participate" pillar would have been a political impossibility given certain rejection by states (like China and Russia) - and even by civil society actors themselves. This posture nonetheless seems to ignore the large number of treaties that are regularly adopted by states with civil society "participation rights" embedded expressly within them (see, e.g., note 44 above) as well as civil society's organized protagonism in demanding such embedding.

49 Sec, e.g., Beth A. Simmons, Mobilizing for Human Rights: International Law in Domestic Politics (Cambridge 2009). See also Robert Cialdini, Influence: Science and Practice (1985), pp. 92-103 
regardless of whether those commitments are publicly manifested in a formally binding instrument (e.g., a treaty) or nonbinding one (the GPs). The key distinction in this regard is not necessarily between binding and nonbinding commitments, but rather between expressive and inexpressive ones..$^{\circ}$ Expressive commitments are sticky; they encourage a wide audience to monitor their implementation and insist on implementation. Inexpressiveness may serve short-term political ends, but also carries large opportunity costs. Most relevantly in the GP context, it removes the power of civil society actors to use principled commitments to make those commitments stick. That is, to insist on them not as a privilege granted at another party's discretion, but as a normative right authoritatively recognized as a principle of conduct in a human rights-respecting society.

Are there additional ways to directly incorporate such "sticky" norms into the GP framework? Certainly. For instance, civil society groups could organize and sponsor the drafting of a set of "Supplementary Guiding Principles" that addressed the participation and accountability issues left out of the GPs - drawing on and crossreferencing, perhaps, the UN Guiding Principles on Extreme Poverty and Human Rights, which do make participatory empowerment of affected communities a central institutional feature. ${ }^{51}$ Such groups could then lobby states, the Working Group, and other special procedures to request the Human Rights Council to endorse the formal updating of the GPs as a short-term priority.

A different, albeit far less effective and authoritative approach would be to encourage the WG to prepare a thematic report that directly addressed the right to participate in GP implementation processes at all levels. It could invite participatory interventions by all stakeholders and focus on "best practices" that have been adopted with respect to allowing civil society participation in a wide range of processes encouraged by the GPs. An obvious downside of this approach is that the WG has already, in its first thematic report on indigenous peoples' rights, manifested a disinclination to recognize fully and robustly the participatory rights of affected stakeholders under current international law..$^{52}$ Such an approach, if pursued in isolation, could then set the participatory project backward, rather than taking it forward, even while years would pass before the WG produced any deliverable. While the WG's current membership will soon change, its institutional reluctance to robustly address participation issues is undoubtedly tied closely to the scope of its mandate, itself intimately linked with the acculturative regulatory logic of the GPs. It is unlikely, then, that the WG will significantly change its approach to this issue. Likewise, thematic reports prepared by special procedures lack authoritative standing among many stakeholders; they could not serve to authoritatively

(collecting research showing that people who commit and have their commitments publicized are more likely to keep their commitment, even after the publicity is over).

51 A/HRC/21/39; HRC Res. 21/11 (27 September 2012) (adopting GPs by consensus). 
embed participation within the GP framework, such that it became part of the "dynamic regulatory logic" that drives it. 53

The surest path forward, then, lies in a dual approach: the organized pursuit of a substantive updating of the GP framework with more expressive rights of participation, while simultaneously pursuing the longer-term project of negotiating a treaty instrument that would make those "soft" expressive commitments to participatory governance "hard" for states under international law. Indeed, as studies show, human rights commitments are "stickiest" - and hence most "mobilizable" when those commitments have been made not only expressively but also through binding treaty law. ${ }^{54} \mathrm{I}$ turn to that critical longer-term proposal below.

\section{A BINDING TREATY: WHAT, WHY AND BINDING ON WHOM?}

Calls for a treaty on business and human rights have of course been made recurrently for over half a century. On 26 June 2014, the UN Human Rights Council took an important, if preliminary, step toward that inevitable development. Responding to the coordinated proposals of over ninety states and over 500 civil society organizations, it agreed to establish an Open-Ended Working Group to consider elements of an international treaty on business and human rights. As discussions begin on what those elements should entail, one thing is clear: the heavily promoted idea that human rights groups demand a "command-and-control"-style treaty that directly binds business under international law must be left at the door. Let us be clear: No human rights treaty has ever followed that model, and human rights groups have never promoted it in any human rights treaty negotiation. It is inconceivable to me that they would do so in the BHR context.

Rather, the kind of BHR treaty that human rights NGOs and affected communities are most likely to support is one that-like other human rights treaties - follows an experimentalist approach and focuses on three elements: (1) defining rights in flexible but expressive terms that resonate with the lived experience of rights-holders; (2) embedding express civil society participation rights as tools of engagement throughout its structure and implementation logic, and (3) clarifying states' duties to take all necessary and appropriate measures to respect, protect and ensure human rights as they are impacted by corporate misconduct. In each of these respects, I suggest, the most useful and relevant model lies with the UN's most recently adopted human rights treaty: the UN Convention on the Rights of Persons with

See Albin-Lackey, note 3 above (recognizing problematic nature of GPs "setting a lower bar than international human rights standards" since "many companies now see the principles - incorrectly as the world's definitive, one-stop standard for good human rights practice. There is a risk that many companies will simply ignore standards the Guiding Principles do not echo.") (emphasis added).

54 See, e. g., Simmons, note 49 above; Adam S. Chilton, "The Influence of International Human Rights Agreements on Public Opinion: An Experimental Study," Chicago Joumal of International Law 15 (2014), 110 . 
Disabilities (CRPD). Below, I very briefly note the key elements thereof that are of greatest likely relevance to discussions on a new BHR Treaty. ${ }^{55}$

\section{A. Flexible, but Expressive Commitments}

First, the CRPD does not rigidly prescribe conduct, but rather incorporates a set of flexible, expressive, and experientially, resonant terms designed to enable a wide range of actors to engage them as tools of leverage, mobilization, and participatory engagement in their diverse local struggles. Indeed, largely at the insistence of rightsholder groups and their civil society allies participating in the drafting process, ${ }^{56}$ the UN Committee charged with its negotiation carefully avoided "shopping lists" and overspecification of details and standards as an agreed operational modality. It did so precisely to ensure that the Convention's text would remain relevant and vital over time, space, and context. It is thereby capable of responding to new challenges and modes of abuse as they arise, as well as the vastly different challenges faced by differently situated rights-holders and duty-bearers across the world. It also wished to avoid the negative inference that anything not expressly included in a detailed provision was intended to be excluded. Thus, broadly exemplary terms with inclusive references and a higher level of generality were consistently preferred to overlyspecific, narrowly tailored ones or "lists" of , abuse and standardized implementing measures. The same will undoubtedly be true of a BHR Treaty.

\section{B. Embedding Participation Rights}

Second, to ensure that rights-holders can in fact engage in processes directed at a meaningful incorporation of their rights into policies, practices and procedures that affect them, the CRPD focused on embedding rights-holder participation rights and institutional pathways for their exercise (what I call "participation nodes") throughout its text and dynamic implementation logic. "Full and effective participation [of rights-holders] and inclusion in society" was thus affirmed repeatedly as a core guiding principle of the treaty, reiterated in the Preamble, Purpose, and General Principles. The treaty likewise codified it as a central obligation of all States parties. The "General Obligations" clause, thus commits all public actors, under a "shall" provision, to "closely consult with and actively involve persons with disabilities [PWDs].... [i]n the development and implementation of legislation

Space constraints prevent fuller discussion and analogy between the disability and B\&HR contexts. For more on the CRPD, see, e.g., Tara J. Melish, "The UN Disability Convention: Historic Process, -Strong Prospects, and Why the U.S. Should Ratify," Human Rights Brief 14(2) (2007); Tara J. Melish, "An Eye Toward Effective Enforcement: A Technical-Comparative Approach to the CRPD Negotiations," Human Rights and Disability Advocacy (Sabatello and Shulze (eds.), Penn Press 2013). by the EU, but concluding driving factor was civil society NGOs, and rights-holder groups). 
and policies to implement the present Convention, and in other decision-making processes concerning issues" affecting their lives. ${ }^{57}$ These same participatory rights and duties were repeated and made more operationally specific with respect to key substantive rights, monitoring arrangements, information collection and accessibility, compliance regimes, and oversight systems.

Let me note just a few provisions given their importance for a BHR treaty. First, the provision on national-level implementation and monitoring affirms unambiguously that "[c]ivil society, in particular [PWDs] and their representative organizations, shall be involved and participate fully in the monitoring process." ${ }^{88}$ Another provision specifically requires states to ensure "effective monitoring" by "independent authorities" of "all" facilities and programs designed to serve PWD, whether public and private. ${ }^{59}$ State parties are likewise required to collect and disaggregate data for purposes of policy formulation, and to ensure its accessibility to PWD. At the same time, the CRPD expressly commits States to the establishment of national implementation machinery specifically tasked with responsibility over the treaty's subject matter. It is to and through these instituted processes that rights-holders can direct their collective concerns, demands, inputs and organized oversight. They include (1) a focal point or focal points within government to oversee implementation of the treaty; (2) a coordination mechanism to ensure coherence in policy and action across the public sphere; and (3) a set of independent monitoring mechanisms (like NHRIs) with competence over the treaty's effective implementation. With respect to each of these, states commit to ensure full civil society participation, particularly by the treaty's rights-holders themselves. The same is true of the treaty's international supervisory machinery.

Given the massive power and information disparities that pervade the BHR field, there is little doubt that the same kinds of overlapping commitments to participatory rights of access to decision-making structures and processes - at local, national and international levels - should likewise drive the logic of any new BHR treaty.

\section{Specifying States' Duties}

Finally, for highly instrumental and operationally pragmatic reasons, human rights treaty law has remained centered on clarifying states' duties to respect and ensure human rights. This is true even as human rights law is increasingly applied to every imaginable kind of private conduct. It is indeed precisely in recognition of this reality that the GPs focused on the state (legal) duty to protect human rights from business-related abuse. And, yet, while few dispute the general existence of this duty under international treaty law, there remains significant uncertainty about its sectorspecific operational contours. Indeed, corporate actors have amassed such broad and powerful rights across legal borders that it is increasingly unclear where their 
prerogative ends and what role public law has to define and constrain it. It is precisely here, then, in clarifying the state legal duty to respect, protect, and ensure rights to affected communities, that a "carefully constructed precision tool" is most needed.

In this regard, the former SRSG's repeated assertion that such a treaty would.not "add value" is unpersuasive. It indeed misconstrues the purpose and content of all specialized treaties in the human rights domain. Such treaties do not create "new" rights, but rather serve as precision instruments in clarifying the scope and specialized content of more generally articulated rights and duties with respect to highly abusive subject areas long marginalized or ignored in national agendas and mainstream human rights procedures. Correspondingly, the most valuable role for a BHR treaty lies in more expressively articulating states' obligations under international law to regulate corporate conduct; to prevent abuse from occurring (through safeguard measures, regular oversight, monitoring, etc.); to respond to abuses when and where they occur, diligently and with a view toward guaranteeing against future violations; and to ensure civil society participation and independent mechanisms for monitoring, oversight, and dynamic regulatory response, at local, national and international levels alike. ${ }^{60}$

A precision instrument of this kind would indeed serve multiple power shifting ends. Not only would it create stronger, more precise leverage tools for rights-holders and their advocates to engage states' wrongful acts and omissions directly, but it would also address the elephant in the room: States themselves need new legal tools of empowerment and leverage to be able to regulate and monitor in the business domain. Increased legality and treaty-based specificity around state obligations thus serve to enhance opportunities for state-civil society alliances (often pursed in adversarial terms, but understood covertly as collaborative), while, at the same time, allowing states to expressively self-bind and hence gain legal leverage to assert themselves in their own regulatory role ${ }^{6_{1}}$ (including in multistate or regional arrangements across the Global South). It is little surprise, then, that the principal proponents of a comprehensive treaty are Global South states and civil society organizations - precisely those with least power and fewest rights vis-à-vis the massively resourced and legally powered corporate sector.

\section{LOOKING FORWARD}

In his initial contribution to this volume, César Rodríguez-Garavito invites an immensely important and timely project: creative conversation and strategic thinking from a variety of global voices on the "dynamic dimension" of the GPs. In other

Specialized human rights treaties thus virtually always include obligations clauses that are longer and more articulated than those found in general instruments.

61

See generally Karen J. Alter, The New Terrain of International Law: Courts, Politics, Rights (Princeton Univ. Press 2014) (discussing state delegation of jurisdiction to international fora as a way to self-bind and hence gain power vis-à-vis other actors). 
words, their "capacity to push the development of new norms and practices that might go beyond the initial content of the GPs," thereby ensuring "cumulative, stepby-step progress" in improving companies' real-world compliance with human rights standards. I salute this initiative and hope that my small contribution here will aid it in two ways. First, by encouraging a critical rethinking of the dominant frames used to promote and explain the GPs in public debate, with particular attention to the damaging ways those frames have served to sideline and marginalize the voices, roles, and strategic insights of affected communities and their human rights allies. Second, by helping to ensure that conversations moving forward remain solidly focused on identifying and promoting the tools, procedures, and resources that affected communities themselves need to participate - actively and meaningfully - in the policy and decision-making processes that so affect their lives. If those goals are achieved, I believe, a foundation will have been built upon which we can indeed move the GP framework "beyond the end of the beginning." 